\title{
Controlled stabilisation of silicic acid below pH 9 using poly(1-vinylimidazole)
}

\author{
Vadim V. Annenkov, ${ }^{* a}$ Elena N. Danilovtseva, ${ }^{a}$ Yelena V. Likhoshway, ${ }^{a}$ Siddharth V. Patwardhan ${ }^{b}$ and \\ Carole C. Perry*b
}

Received 23rd October 2007, Accepted 22nd November 2007

First published as an Advance Article on the web 4th December 2007

DOI: $10.1039 / \mathrm{b} 716367 \mathrm{n}$

\begin{abstract}
We show, for the first time, inhibition of silicic acid condensation over a wide range of $\mathrm{pH}$, especially below 9 using certain molecular mass fractions of poly(1-vinylimidazole) (PVI). This is achieved by stabilisation of molybdate-active $S i$ species, which are crucial to condensation and growth to form silica. The structure of the resulting composites depends on the molecular mass of the PVI chains. Long-chain macromolecules can "encapsulate" Si species giving rise to stable soluble complexes. Short PVI chains stimulate association of silica particles and at neutral $\mathrm{pH}$ precipitation occurs. Protonation of imidazole units in acidic $\mathrm{pH}$ results in dissolution of the precipitates. We believe that the results presented herein using PVI as a model system will help elucidate the mechanisms underpinning the molecular interactions between (bio)macromolecules and inorganic materials.
\end{abstract}

\section{Introduction}

Silicic acid, which is a dissolved form of silica, is found in natural waters such as oceans, rivers and lakes. It is in equilibrium with silica and silicates from rocks and soils with an equilibrium solubility of $\sim 100 \mathrm{ppm}(\sim 2 \mathrm{mM})$ at around $25{ }^{\circ} \mathrm{C}$. ${ }^{1}$ Above this concentration, silicic acid undergoes condensation or polymerisation thus reducing silicic acid concentrations to its equilibrium solubility and generating stable oligomeric and/or polymeric species (i.e. silica). ${ }^{2}$ The polymerisation of silicic acid to produce silica is a complex process involving polymerisation to form stable nuclei; growth of nuclei leading to fundamental particles; and particle aggregation to form branched networks, larger particles or other structures. During the first stage of polymerisation, silicic acid concentrations rapidly reduce while later stages are dominated by dissolution and precipitation of silicic acid followed by maturation.

The polymerisation profile and properties of the product formed are highly dependent on solution $\mathrm{pH}$ and the presence of additives such as electrolytes (both organic and inorganic). ${ }^{2}$ Additives are also known to affect a wide range of materials properties including morphology and porosity. Recently, bioinspired additives have been explored and shown to catalyse silica polymerisation, promote silica aggregation and/or serve as templates in silica formation at circumneutral $\mathrm{pH}^{3,4}$

In nature, organisms such as diatoms, radiolaria and sponges are all known for their ability to produce silica in vivo by utilising soluble silica from their respective aqueous environments. ${ }^{5,6}$ Silicic acid which is present at undersaturated

\footnotetext{
${ }^{a}$ Limnological Institute of Siberian Branch of Russian Academy of Sciences, 3, Ulan-Batorskaya St., P.O. Box 4199, Irkutsk, 664033, Russia.E-mail: annenkov@lin.irk.ru

${ }^{b}$ Biomolecular and Materials Interface Research Group, School of Biomedical and Natural Sciences, Nottingham Trent University, Clifton Lane, Nottingham, UK NG118NS.E-mail:Carole.Perry@ntu.ac.uk
}

concentrations in oceans, rivers and lakes, is actively taken up by organisms, transported within cells and polymerised - all in a controlled fashion-and for many of the processes, biomolecules are known to be involved..$^{7-10}$ It has been shown that during intracellular transport, silicic acid in diatoms, for instance, is supersaturated with levels of 19-340 mM being recorded. ${ }^{8,9}$ However, direct solid-state ${ }^{29} \mathrm{Si}$ NMR measurements on living diatoms has not detected any free silicic acid. ${ }^{11}$ Moreover, a signal from $\mathrm{Q}^{1}$ silicon $\left[\equiv \mathrm{Si}-\mathrm{O}-\mathrm{Si}(\mathrm{OH})_{3}\right]$ was not observed and the $\mathrm{Q}^{2}$ signal $\left[(\equiv \mathrm{Si}-\mathrm{O})_{2}-\mathrm{Si}(\mathrm{OH})_{2}\right]$ was very weak implying the absence of free silicic acid and short linear oligomers. These data might suggest the existence of silicon in the form of "active" soluble silica, perhaps stabilized by organic biomolecules. However, the stabilisation of silicic acid using organic molecules has not been demonstrated yet at biologically relevant $\mathrm{pH}(\mathrm{pH}<8)$.

Of particular interest to this investigation are charged polymeric additives which have been shown to promote rapid silica condensation at circumneutral $\mathrm{pH}$ producing silicas with unique structure and morphology. ${ }^{3}$ In contrast, polyols have been shown to stabilise silicic acid but only under highly basic conditions $^{12,13}$ and have no such effect at neutral $\mathrm{pH}^{.14}$ The study of molecular interactions between (bio)macromolecules and silica species is complicated due to several processes occurring in parallel: condensation of silicic acid; catalysis of silanol condensation with polymer units; as well as association of silicic acid and its oligomers with the polymer chain. This variety of possible simultaneous reactions is one of the reasons that there is a poor understanding of the nature of molecular level interactions between silica oligomers and additives in spite of its importance in chemistry, biology and material sciences.

Recently we have shown that poly(1-vinylimidazole) (PVI) is capable of forming insoluble complexes with poly(silicic acid) (PSA) species and is active in co-operative complex formation with weak polymeric acids. ${ }^{15,16}$ The PVI-PSA precipitates 
were found to be stabilized by hydrogen bonds and exhibited near equimolar composition. However, the PVI samples used were not fractionated and contained a wide range of molecular mass fractions. It is interesting to note that PVI, which possesses imidazole functionality analogous to histidine, possesses low basicity $\left(\mathrm{p} K_{\mathrm{BH}}{ }^{+}=5-6\right)$ and is uncharged at $\mathrm{pH} \geqslant 7^{17}$ in contrast to the polymeric amines studied previously in silica formation where $\mathrm{p} \mathrm{BHH}^{+}>9 .{ }^{3}$ In this study, we use PVI, an inexpensive polymer, as a model compound to investigate how biological and synthetic polymers interact with primary silicic acid species. In particular, we investigate the effect of narrow molar mass fractions of PVI (7 to $530 \mathrm{kDa}$ ) on the condensation of silicic acid.

\section{Experimental}

\section{Materials}

Sodium silicate $\left(\mathrm{Na}_{2} \mathrm{SiO}_{3}\right)$ nonahydrate used as the silica precursor was obtained from Sigma-Aldrich. Standard hydrochloric acid solution (1 M) was purchased from Fisher. Reagents used for the molybdosilicate kinetic assay were as previously reported. ${ }^{18}$ PVI samples were synthesised as described below.

A high-molecular-weight PVI sample (160 kDa) was obtained by polymerization of 1-vinylimidazole in benzene in the presence of 2,2-azobis(isobutyronitrile) according to a previously reported method. ${ }^{19}$ Low-molecular-weight PVI (35 kDa) was synthesized by polymerization of a $33 \%$ solution of 1 -vinylimidazole in ethanol in the presence of $3 \%$ (by monomer mass) of 2,2-azobis(isobutyronitrile) in ampoules at $60{ }^{\circ} \mathrm{C}$ for $16 \mathrm{~h}$. Both PVI samples were precipitated into diethyl ether, purified by double precipitation from ethanol into diethyl ether and dried under vacuum. The yield of the polymers was $75-85 \%$. Fractionation of PVI was performed by the stepwise precipitation from ethanolic solution $\left(14 \mathrm{~g} \mathrm{~L}^{-1}\right.$ of the high-molecular-weight sample and $40 \mathrm{~g} \mathrm{~L}^{-1}$ of the lowmolecular-weight PVI) with acetone at $20{ }^{\circ} \mathrm{C}$. The obtained coacervates were precipitated into diethyl ether and dried under vacuum.

\section{Methods}

The molecular weight of the PVI samples was determined by viscometry using the Mark-Houwink-Sakurada equation with parameters taken from the literature. ${ }^{20}$ Potentiometry measurements of PVI solutions with or without sodium silicate were conducted in a temperature-controlled cell at $20 \pm 0.1{ }^{\circ} \mathrm{C}$ using a Multitest IPL-113 ionometer with a combined $\mathrm{pH}$ electrode. PVI solutions were titrated against standard 0.1 M HCl.

Solutions of ' $\mathrm{Si}$ ' were prepared from a $0.1 \mathrm{M}$ stock solution of sodium silicate $(\mathrm{pH} \sim 12)$. For the stock solution it was found that detectable condensation started only after 1 month as recorded by the molybdosilicate method. PVI fractions were mixed with sodium silicate solution such that the final concentration of repeating units in PVI was $5.3 \mathrm{mM}$ and [Si] was $7.8 \mathrm{mM}$ unless otherwise specified. Dynamic light scattering (DLS) was performed on samples in order to measure particle or aggregate size. In addition, free silicic acid concentration after a given time was determined using a well-established molybdosilicate blue method. ${ }^{18}$ The errors associated with the molybdosilicate blue method are typically $<5 \%$. It is known that some reagents can hinder the accurate measurements of $\mathrm{Si}(\mathrm{OH})_{4}$ by this method. ${ }^{2}$ However, we have found that PVI at $5.3 \mathrm{mM}$ concentration does not influence the molybdosilicate assay with undersaturated $(0.5-1 \mathrm{mM})$ concentrations of silicic acid (data not shown). At the concentrations of $<8 \mathrm{mM} \mathrm{Si}$ (not isotopically enriched), NMR was unable to provide any information even after accumulating scans over several hours.

The PVI-sodium silicate solutions were slowly neutralised to $\mathrm{pH} 10$ with $0.1 \mathrm{M} \mathrm{HCl}$ over $30 \mathrm{~min}$ and kept undisturbed for 30 min before DLS experiments were carried out. The next portion of $\mathrm{HCl}$ was added after $1 \mathrm{~h}$ and the procedure repeated. DLS data were collected using a Coulter N4Plus instrument with a $\mathrm{He}-\mathrm{Ne}(632.8 \mathrm{~nm})$ laser supply, 5-10 repetitions and run time $30-300 \mathrm{~s}$. The obtained data (autocorrelation function) were transferred into the CONTIN program and were treated according to recommendations of the program manual. ${ }^{21,22}$ Error bars shown for the DLS data arise from a combination of polydispersity in particle size, flexibility of polymeric chains and random error. $\zeta$-Potential measurements of samples were performed using a Zetasizer Nano ZS from Malvern Instruments using a disposable capillary cell.

Precipitates, where present, were collected, lyophilised and analysed for surface area and porosity using a Quantachrome Nova 3200e surface area and pore size analyzer. Before every run, samples were degassed at $80{ }^{\circ} \mathrm{C}$ overnight under vacuum. Samples for scanning electron microscopy (SEM) were prepared from precipitates suspended in solution by placing drops on aluminium sample holders, cooling with liquid nitrogen, drying in vacuum and plasma-coating with gold using a SDC 004 (BALZERS) sputter coater. For transmission electron microscopy (TEM) studies, a drop of solution containing the sample was placed on to a copper grid coated with a Formvar film and the samples air dried. SEM analysis was performed using a Philips SEM $525 \mathrm{M}$ and TEM with a Zeiss EM Leo 906E instrument.

\section{Results and discussion}

\section{Characterisation of PVI samples}

Two PVI samples of average molar mass (MM) 35 and $160 \mathrm{kDa}$ were synthesised as described above and separated into seven fractions by stepwise precipitation. Seven fractions covering the MM interval from 7 to $530 \mathrm{kDa}$ were chosen for further experimentation (labelled as PVI- $x$ where $x$ is MM in $\mathrm{kDa}$ ). In order to investigate the interactions between PVI polymers and silicic acid species, it is important to study the solution behaviour of PVI fractions in the absence of silicic acid. This was achieved by using two methods: titration of PVI polymers against standard $\mathrm{HCl}$ and determination of PVI polymer coil sizes in $\mathrm{HCl}$ solutions. The titration curves for all PVI fractions studied are shown in Fig. 1a. It can be seen that the titration curves for a range of MM fractions are alike, except when the initial $\mathrm{pH}$ (without the addition of any $\mathrm{HCl}$ ) is considered (Fig. 1a inset). Clearly, the low MM polymers 

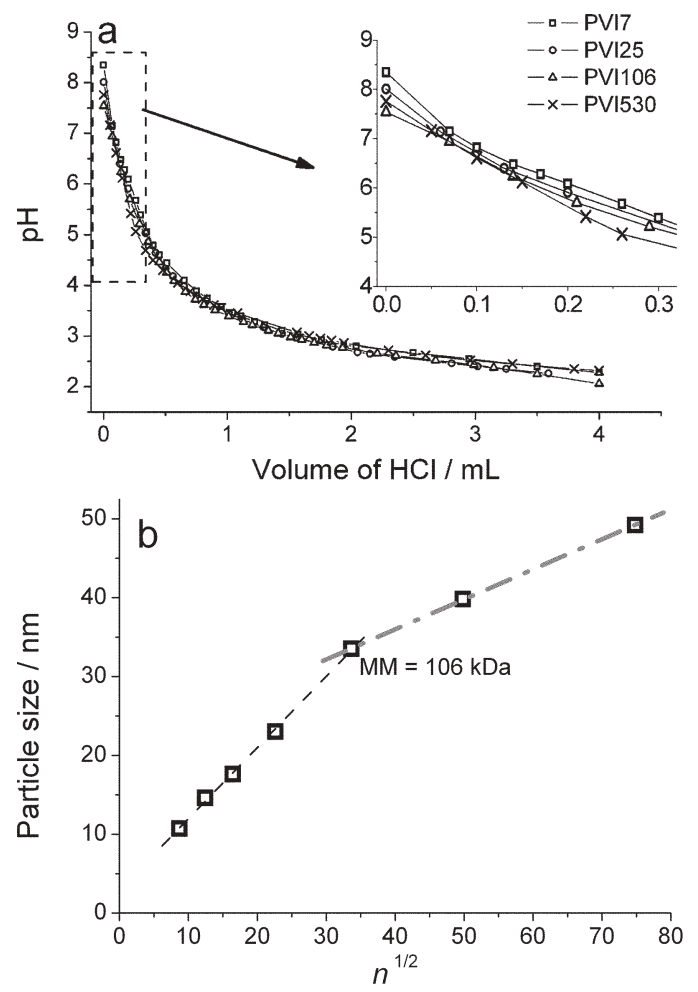

Fig. 1 Solution behaviour of PVI fractions: (a) titration profiles and (b) macromolecule coil sizes where $n$ is the degree of polymerisation. Inset in (a) shows the plot area highlighted by the box. Particle sizes were obtained from $20 \mathrm{mM}$ solutions $(5.3 \mathrm{mM}$ solutions of PVI alone contained too few particles for determination by DLS).

(PVI-7 and PVI-25) are only slightly more basic (initial $\mathrm{pH}>8$ ) than the higher molar mass fractions (initial $\mathrm{pH} \sim 7.5-7.7$ ).

The sizes of PVI polymers in $0.1 \mathrm{M} \mathrm{HCl}$ were studied using DLS and the data are plotted in Fig. 1b. As expected, the size of the macromolecular coils was found to be proportional to the square root of the degree of polymerization, i.e. the number of monomer units $n$ in a given fraction. Two linear regions were apparent: for low MM and for higher MM, with the $106 \mathrm{kDa}$ fraction $\left(n^{1 / 2}=33.6\right)$ being the point of transition. Our data obtained from DLS measurements are consistent with the literature where a similar discontinuity between lowand high-molecular-weight PVI samples has been reported for PVI in methanolic solutions using static light scattering and viscometry ${ }^{20}$ thus confirming the reliability of DLS analysis. The observed transition in the coil size and the protonation behaviours may arise from intra-coil interactions of the polymers, although extensive experimentation would be required in order to fully address this issue. The sizes of PVI macromolecules do not depend on pH (Fig. 2b) and slightly dropped at $\mathrm{pH} 4-5$ which is probably due to the partial protonation of weakly basic imidazole rings and the formation of intramolecular hydrogen bonds: ${ }^{23}$<smiles></smiles>
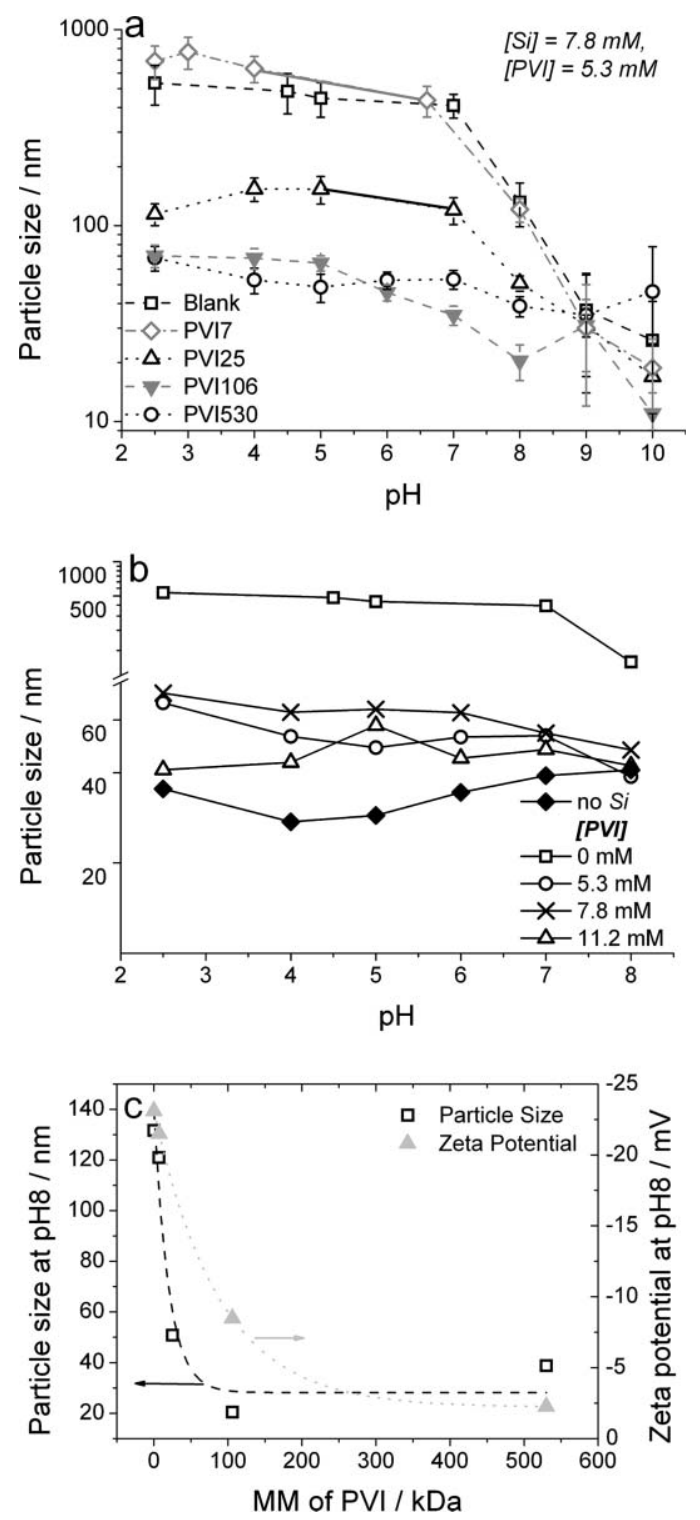

Fig. 2 (a) Particle size measurements for sodium silicate and PVI systems by varying PVI MM keeping constant $[\mathrm{Si}]=7.8$ and $[\mathrm{PVI}]=$ 5.3. Solid lines in (a) represent the region where precipitation was observed. (b) Particle size measurements for sodium silicate and PVI systems for PVI-530 with and without the presence of sodium silicate keeping [Si] constant at $7.8 \mathrm{mM}$, varying [PVI]. (c) ל-Potential measurements at $\mathrm{pH} 8$ for samples shown in (a).

\section{Interactions of PVI samples with silicic acid species}

In order to investigate the interactions between a range of PVI molar mass fractions and silicic acid species, a systematic study was carried out as follows. Solutions containing $7.8 \mathrm{mM}$ sodium silicate and $5.3 \mathrm{mM}$ PVI were prepared and titrated against $0.1 \mathrm{M} \mathrm{HCl}$. For low $\mathrm{MM}$ fractions $(\mathrm{MM}=7,14,25$ and $48 \mathrm{kDa}$ ), precipitation was observed at circumneutral $\mathrm{pH}$ which is consistent with previous reports where silica polymerisation has been studied in the presence of synthetic and biological macromolecules. ${ }^{3,4}$ However, the precipitates dissolved in acidic media $(\mathrm{pH}<4-5)$ and the range of $\mathrm{pH}$ over which the precipitates were stable increased with the decrease 
Table 1 Neutralization of sodium silicate in the presence of PVI

\begin{tabular}{lll}
\hline PVI fraction & $\begin{array}{l}\text { PVI size without } \\
\text { sodium silicate }{ }^{a} / \mathrm{nm}\end{array}$ & $\begin{array}{l}\text { Insolubility } \\
\text { region }(\mathrm{pH})\end{array}$ \\
\hline PVI-7 & $10.7 \pm 4$ & $7.5-3.9$ \\
PVI-14 & $14.6 \pm 5$ & $7.6-5.2$ \\
PVI-25 & $17.6 \pm 8$ & $8.0-5.6$ \\
PVI-48 & $23.0 \pm 9$ & $8.1-6.5$ \\
PVI-106 & $33.5 \pm 11$ & No precipitation \\
PVI-240 & $39.8 \pm 10$ & No precipitation \\
PVI-530 & $49.2 \pm 8$ & No precipitation \\
${ }^{a}$ In $0.1 \mathrm{M} \mathrm{HCl}$; data from Fig. 1b and 2a. & \\
\hline
\end{tabular}

of MM (Table 1). Furthermore, increasing PVI concentration up to $28 \mathrm{mM}$ while keeping [Si] constant at $7.8 \mathrm{mM}$ did not prevent precipitation. This behaviour of the $\mathrm{Na}_{2} \mathrm{SiO}_{3}-\mathrm{PVI}-$ $\mathrm{HCl}$ system is in disagreement with the expected stability of silica over a range of $\mathrm{pH}$, where silica is usually only soluble at $\mathrm{pH}>8$. Interestingly, as the MM of PVI increased above $106 \mathrm{kDa}$, no precipitation was observed and the solutions remained homogeneous over the entire $\mathrm{pH}$ range studied ( $\mathrm{pH} \sim 3-10)$. This observation is in direct contrast with the literature where synthetic and biological macromolecules have been shown to precipitate silica. ${ }^{3,4}$ It is interesting to note that the transition from the formation of precipitates to solutions that remain homogeneous occurs at around the PVI fraction of $106 \mathrm{kDa}$ which coincides with the transition of the macromolecular solution size presented in Fig. 1b. The observation that supersaturated solutions of silicic acid remain homogeneous over some or the entire $\mathrm{pH}$ range in the presence of PVI of a range of molar mass could mean that either PVI is inhibiting the growth of silica oligomers and particles or the presence of the polymer is inhibiting the silicic acid condensation altogether. Both possibilities were investigated using DLS and molybdosilicate assays respectively and the results obtained are described below.

With the aim being to study the growth of silica particles in solution we used DLS for samples of MM 7, 25, 106 and $530 \mathrm{kDa}$. The particle size data obtained at a fixed initial silicon concentration $(7.8 \mathrm{mM})$ and PVI concentration $(5.3 \mathrm{mM}$ with respect to the repeating unit) for a range of PVI molar masses are presented in Fig. 2a. The initial pH of the sodium silicate solutions with or without the addition of PVI samples was adjusted to 10 . In the absence of PVI (blank sample), the particle size increased from $26 \mathrm{~nm}$ to $410 \mathrm{~nm}$ when the $\mathrm{pH}$ was reduced from 10 to 7 , while further addition of $\mathrm{HCl}$ (decreasing $\mathrm{pH}$ to 2.5 ) increased particle size only slightly to $534 \mathrm{~nm}$. For the sodium silicate solutions in the presence of PVI samples, the particle size was $<50 \mathrm{~nm}$ at $\mathrm{pH} 9-10$, which is roughly comparable with the size of free polymer molecules in $\mathrm{HCl}$ solutions (Fig. 1b). The presence of PVI-7 followed a trend similar to the blank sample, however, precipitation was observed between pH 7.5 to 3.9 (marked by a solid line on the PVI-7 curve in Fig. 2a) and the precipitate re-dissolved for $\mathrm{pH}<3.9$. In the presence of PVI-25, although the curve shows a trend similar to the blank system, the particle sizes were quite small $(50-100 \mathrm{~nm})$ when compared to those formed in the blank system. In the presence of PVI-106 and 530, however, dramatic changes in the particle growth profiles were observed. Between the $\mathrm{pH}$ range $10-2.5$, the particles grew only from $\sim 10 \mathrm{~nm}$ to $\sim 70 \mathrm{~nm}$ for PVI-106 and $\sim 35 \mathrm{~nm}$ to $\sim 70 \mathrm{~nm}$ for PVI-530, thus indicating that particle growth was inhibited in the presence of the higher molar mass PVI fractions.

The inhibition of particle growth in the presence of high MM PVI fractions was further investigated using PVI-530 by varying PVI concentration but keeping silicon concentration constant and the results are shown in Fig. 2b. The curve for particle growth for the blank sample is also plotted in Fig. 2b for comparison. In addition, the size of PVI-530 in the absence of sodium silicate over a range of $\mathrm{pH}$ is also presented. The size of PVI macromolecules in the absence of sodium silicate slightly dropped at $\mathrm{pH} 4-5$ which is probably due to the partial protonation of weakly basic imidazole rings and the formation of intramolecular hydrogen bonds. For any of the PVI-530 concentrations studied, no particle growth was observed (particle size remained around 40-60 $\mathrm{nm}$ ) and the sizes were comparable with the size of PVI-530 in the absence of sodium silicate. These results confirm that higher MM PVI samples inhibit particle growth.

In order to examine the protonation effects of both PVI and silica species on the net charge of the PVI-Si system, $\zeta$-potential measurements were performed at $\mathrm{pH} 8$ and 4 where no precipitation was observed for any of the samples. The data obtained from $\zeta$-potential experiments at $\mathrm{pH} 8$ are presented in Fig. 2c along with the particle sizes measured at the same $\mathrm{pH}$. It can be clearly seen that as the MM increases from zero (blank) to 530, particle size drops drastically from $\sim 130 \mathrm{~nm}$ to $\sim 40 \mathrm{~nm}$. Interestingly, an identical trend is observed for the $\zeta$-potential data. In the absence of PVI (blank), the $\zeta$-potential is $-23.1 \mathrm{mV}$ at $\mathrm{pH}$. When the PVI samples were added to the sodium silicate solutions, $\zeta$-potential decreases rapidly with increasing PVI MM such that it drops to $-2.8 \mathrm{mV}$ for PVI-530. This behaviour suggests that at a given $\mathrm{pH}, \mathrm{PVI}$ fractions are able to partially neutralise the particle charge in a molecular mass dependent fashion. It is worth noting that all the PVI fractions yield identical titration curves (Fig. 1a), i.e. possess similar protonation behaviour. The only difference between PVI fractions is their size in solution in the absence and presence of $S i$ (Fig. $1 \mathrm{~b}$ and $2 \mathrm{a}$ respectively). The $\zeta$-potential experiments performed at $\mathrm{pH} 4$ did not generate any useful data due to the low counts recorded. One reason could perhaps be the lack of charged species in solution probably due to the partial protonation of weakly basic imidazole rings as well as the low charge of the silica species present (point of zero charge for silica is $\sim 3^{2}$ ).

After establishing that the particle stabilisation effect observed for high MM PVI fractions is related to the extent of charge neutralisation ability, we sought to study the nature of $\mathrm{Si}$ species that are being stabilised. This was achieved by examining silicic acid condensation for the range of samples prepared for the DLS study using the molybdosilicate blue assay. The silicic acid concentration for the blank sample remained almost unchanged around 3-3.5 mM (i.e. $\sim 50-60 \%$ initial silicic acid had reacted) over the $\mathrm{pH}$ range 2.5-7 while the free silicic acid concentration increased to $5 \mathrm{mM}$ and $6.3 \mathrm{mM}$ at $\mathrm{pH} 8$ and 10 respectively (Fig. 3). The trend of free silicic acid concentration with $\mathrm{pH}$ for the blank system is similar to the silica solubility reported in the literature (p. 48 of ref. 2). The only significant difference is the lower silicic acid 


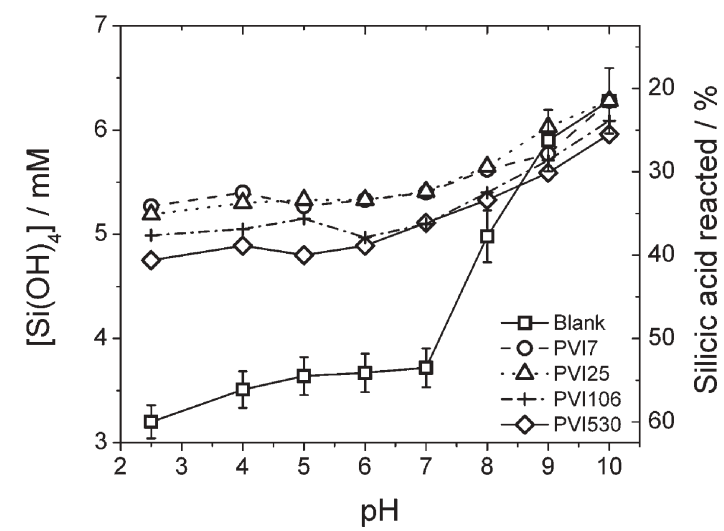

Fig. 3 Molybdate-active silicic acid measured for samples under conditions identical to those in Fig. 2a using the molybdosilicate blue assay for sodium silicate with or without the presence of PVI over the $\mathrm{pH}$ range $2.5-10$.

concentrations in the latter at equilibrium when compared with our data. This difference is simply due to the fact that our samples had not been left to reach equilibrium. However, when allowed to condense longer, equilibrium was achieved where the silicic acid concentration was measured to be $\sim 2.5 \mathrm{mM}$ (data not shown) and is consistent with the literature.

The free silicic acid concentration recorded in the presence of PVI samples is also plotted in Fig. 3. It is very interesting to note that the free silicic acid concentrations in the presence of PVI samples is higher $(\sim 5-6 \mathrm{mM})$ than that in the blank system for the $\mathrm{pH}$ range $2.5-8$, however, at $\mathrm{pH}>8$, this effect diminished. The data suggest that in the presence of PVI samples, less than $30 \%$ of the initial silicic acid had reacted while the remaining $70 \%$ or higher was still molybdate-active and is intriguing when compared with the blank system where $>50 \%$ of the silicic acid was condensed and inactive to the molybdosilicate assay.

Discussing the inhibition of condensation of silicic acid we must remember that this reaction proceeds mainly by interactions between uncharged $\equiv \mathrm{Si}-\mathrm{OH}$ and anionic $\equiv \mathrm{Si}-\mathrm{O}^{-}$ species. ${ }^{2}$ Silicic acid is a very weak acid $\left(\mathrm{p} K_{\mathrm{a}} \sim 9.8\right)$ and it is practically unionized near neutral $\mathrm{pH}$. Primary poly(silicic acid) particles show more acidic behaviour ( $\left.\mathrm{p} K_{\mathrm{a}} \sim 6-7\right)$, so that the condensation at $\mathrm{pH}<8$ is realised mostly on these particles/species. PVI may complex with silica by hydrogen bonds, ${ }^{15}$ in contrast to polymeric amines which can interact via ionic bonds $\equiv \mathrm{Si}-\mathrm{O}^{-}{ }^{+} \mathrm{N} \equiv$. The inhibition of silicic acid condensation is slightly more pronounced with PVI-530 and 106 which also prevents precipitation. Thus, stabilization of growing silica particles in the unionized form by complexing with PVI may provide an explanation for the decrease in the extent of condensation. Indeed, the $\zeta$-potential measurements (Fig. 2c) show that PVI-106 and PVI-530 are capable of shielding the charge present on $\mathrm{Si}$ species in solution.

Interaction between silica particles and PVI chains is a special case of cooperative interpolymeric interactions which are well-studied for linear polymers. ${ }^{24}$ In these systems, if the chain length of one component is much greater than the other, so-called non-stoichiometric soluble complexes can be obtained. Non-bonded units of the longer polymer act as

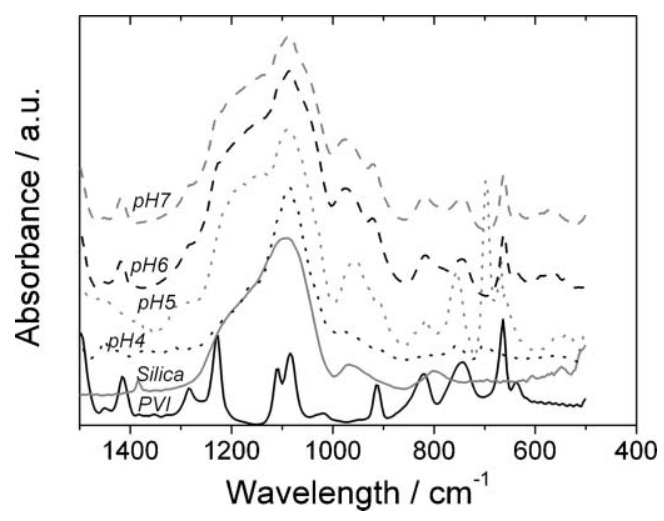

Fig. 4 FTIR spectra of PVI-7 and PVI-7-silica composites synthesised at a range of $\mathrm{pH}$ values. For comparison, spectra for pure PVI and pure silica are also shown.

lyophilisation agents. Non-stoichiometric complexes between polymeric cations and silica nanoparticles have been described previously. ${ }^{24,25}$ Such soluble complexes can also exist with high MM PVI fractions. Complexing of primary silica particles with PVI chains may in turn prevent further silica growth. In the case of low MM PVI the chain length is not sufficient for complete capturing of the silica species and complexation with the organic polymer decreases the solubility of the composite with a resulting growth of particle size and consequent precipitation.

FTIR analysis of precipitates was performed on selected samples and the data are presented in Fig. 4. The spectrum from PVI in the absence of any silica contains bands of stretching vibrations of cyclic imidazole species (1500, 1406, 1286 , and $1228 \mathrm{~cm}^{-1}$ ), stretching vibrations of azole $\mathrm{C}-\mathrm{H}$ (1110 and $1082 \mathrm{~cm}^{-1}$ ) and bending vibrations of the heterocycle $\left(917,827,744,661 \mathrm{~cm}^{-1}\right)$. The presence of these bands in silica samples in addition to silica bands $\left(\sim 1100 \mathrm{~cm}^{-1}\right)$ confirms the formation of silica-PVI composites (Fig. 4) and is consistent with the data presented for non-fractionated PVI samples. ${ }^{15}$ Electron microscopy (Fig. 5) shows that the precipitates obtained in the presence of low MM PVI consist of 100-200 nm particles which agglomerate resulting in larger particles with a smooth surface (Fig. 5a-g). TEM analysis of solution samples prepared in the presence of high MM PVI (Fig. 5h, i) also contain some electron-dense particles with size $<100 \mathrm{~nm}$ which correspond to the DLS data (Fig. 2a). The surface areas of the composite precipitates are relatively low: 26.2 and $88.8 \mathrm{~m}^{2} \mathrm{~g}^{-1}$ for PVI-7 at $\mathrm{pH} 6$ and 7; and 46.3 and $8.1 \mathrm{~m}^{2} \mathrm{~g}^{-1}$ for PVI-14 at $\mathrm{pH} 6$ and 7 respectively. These values are close to the lower end of the data measured for diatom biosilica ${ }^{25}\left(9-269 \mathrm{~m}^{2} \mathrm{~g}^{-1}\right)$ and arise from the smoothing of silica structures by the organic polymer.

\section{Conclusions}

We show, for the first time, that certain PVI fractions are capable of inhibiting silicic acid condensation over a wide range of $\mathrm{pH}$, especially at $\mathrm{pH}<9$, by stabilising $S i$ species which take part in the rate-limiting step of the condensation. The structure of the resulting composite particles depends on the molecular mass of PVI chains (Scheme 1). Long-chain 


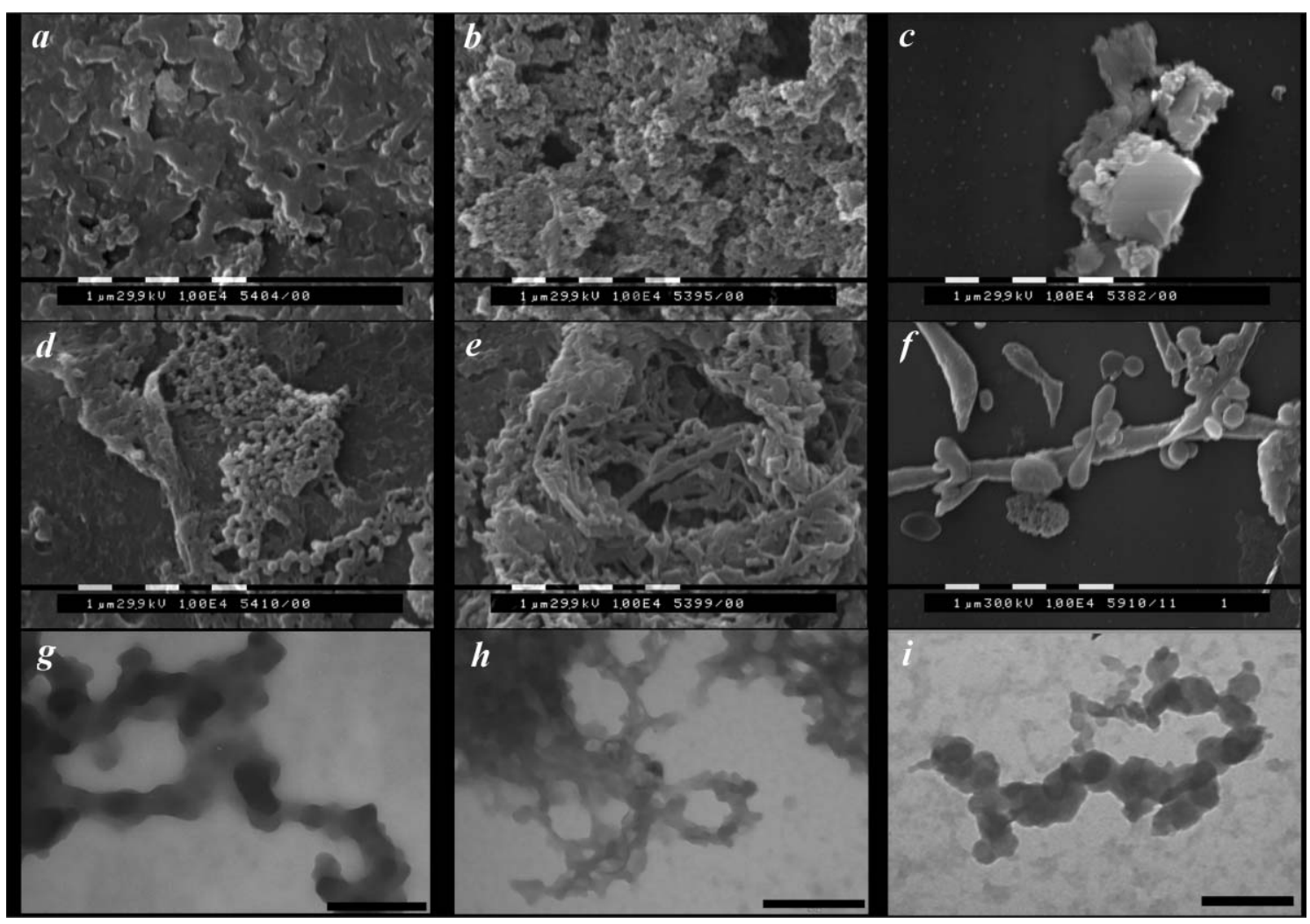

Fig. 5 SEM (a-f) and TEM (g-i) images of PVI-silica composites. MM of PVI: 7 (a-c), 25 (d-g), 106 (h) and 530 (i) kDa. pH: 7 (a, d, g-i), 6 (b, e) and 5 (c, f). Scale bar: $1 \mu \mathrm{m}(\mathrm{a}-\mathrm{f})$ and $200 \mathrm{~nm}(\mathrm{~g}-\mathrm{i})$.

macromolecules give rise to stable soluble $\mathrm{Si}$-PVI complexes. Short PVI chains stimulate the association of silica particles and at neutral $\mathrm{pH}$ precipitation occurs. Protonation of imidazole units under acidic conditions results in dissolution of the precipitate. It is proposed that the ability of PVI fractions to stabilise $S i$ species is related to the property of PVI to partially neutralise the charge on $\mathrm{Si}$ species which is in turn dependent on the PVI MM and their protonation profile. We believe that the results presented herein are of importance to chemists, materials scientists and biologists in respect of the development of routes to materials with improved properties and in the understanding of how biological organisms control materials synthesis.

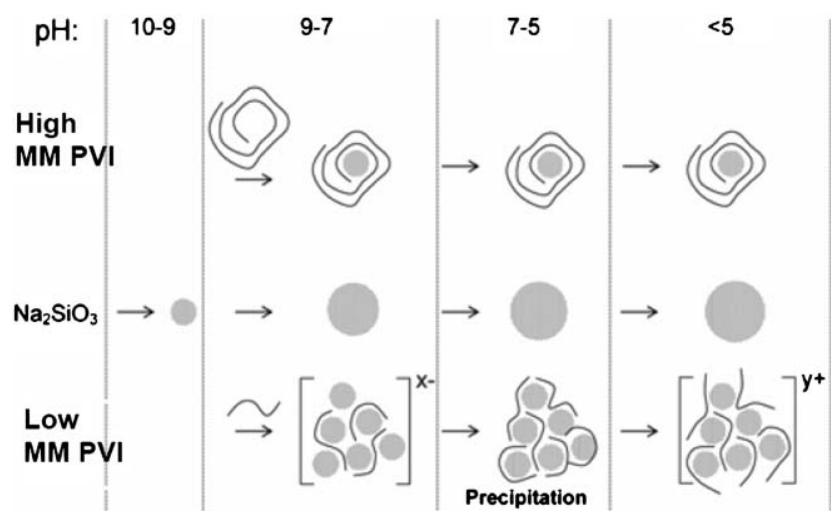

Scheme 1 Scheme of reactions under neutralization of sodium silicate and its mixtures with low and high MM PVI.

\section{Acknowledgements}

This work was supported by INTAS-SB RAS grant (project 06-1000013-8569), the Russian Foundation for Basic Research (project 06-03-32931), a Royal Society International Joint Project between NTU and LIN, AFOSR and EU.

\section{References}

1 P. Treguer, D. M. Nelson, A. J. Vanbennekom, D. J. Demaster, A. Leynaert and B. Queguiner, Science, 1995, 268, 375-379.

2 R. K. Iler, The Chemistry of Silica, John Wiley \& Sons, New York, 1979.

3 S. V. Patwardhan, S. J. Clarson and C. C. Perry, Chem. Commun., 2005, 1113-1121.

4 P. J. Lopez, C. Gautier, J. Livage and T. Coradin, Curr. Nanosci., 2005, 1, 73-83.

5 Silicon and Siliceous Structures in Biological Systems, ed. T. L. Simpson and B. E. Volcani, Springer-Verlag, New York, 1981.

6 Silicon Biomineralization, ed. W. E. G. Müller, Springer, Berlin, 2003.

7 R. Tacke, Angew. Chem., Int. Ed., 1999, 38, 3015-3018.

8 M. Hildebrand, in Biomineralization: From Biology to Biotechnology and Medical Application, ed. E. Baeuerlein, Wiley, Weinheim, Editon edn, 2000, pp. 171-188.

9 M. Hildebrand and R. Wetherbee, Prog. Mol. Subcell. Biol., 2003, 33, $11-57$

10 C. C. Perry, Rev. Mineral. Geochem., 2003, 54, 291-327.

11 R. Bertermann, N. Kroger and R. Tacke, Anal. Bioanal. Chem., 2003, 375, 630-634.

12 S. D. Kinrade, J. W. Del Nin, A. S. Schach, T. A. Sloan, K. L. Wilson and C. T. G. Knight, Science, 1999, 285, 1542-1545.

13 J. B. Lambert, G. Lu, S. R. Singer and V. M. Kolb, J. Am. Ceram. Soc., 2004, 126, 9611-9625.

14 G. T. Tilburey, S. V. Patwardhan, J. Huang, D. Kaplan and C. C. Perry, J. Phys. Chem. B, 2007, 111, 4630-4638. 
15 V. V. Annenkov, E. N. Danilovtseva, E. A. Filina and Y. V. Likhoshway, J. Polym. Sci., Part A: Polym. Chem., 2006, 44, 820-827.

16 V. V. Annenkov, N. L. Mazyar, V. A. Kruglova and S. M. Ananiev, J. Mol. Liq., 2001, 91, 109-114.

17 N. L. Mazyar, V. V. Annenkov, V. A. Kruglova, S. M. Ananiev, E. N. Danilovtseva, A. V. Rokhin and S. V. Zinchenko, Russ. Chem. Bull., 2000, 49, 2013-2017.

18 D. Belton, G. Paine, S. V. Patwardhan and C. C. Perry, J. Mater. Chem., 2004, 14, 2231-2241.

19 N. Pekel and O. Guven, Colloid Polym. Sci., 1999, 277, 570-573.
20 V. E. Eskin, S. Y. Magarik, U. B. Zhuraev and G. D. Rudkovskaya, Vysokomol. Soedin., Ser. A, 1978, 20, 2219-2223.

21 S. W. Provencher, Comput. Phys. Commun., 1982, 27, 229-242.

22 S. W. Provencher, CONTIN users manual (version 2), 2001, http:// s-provencher.com

23 P. M. Henrichs, L. R. Whitlock, A. R. Sochor and J. S. Tan, Macromolecules, 1980, 13, 1375-1381.

24 V. Y. Baranovsky, S. A. Suchishvili, V. A. Kasaikin and V. A. Kabanov, Eur. Polym. J., 1993, 29, 111-114.

25 L. N. Ermakova, P. V. Nuss, V. A. Kasaikin, A. B. Zezin and V. A. Kabanov, Vysokomol. Soedin., Ser. A, 1983, 25, 1391-1399.

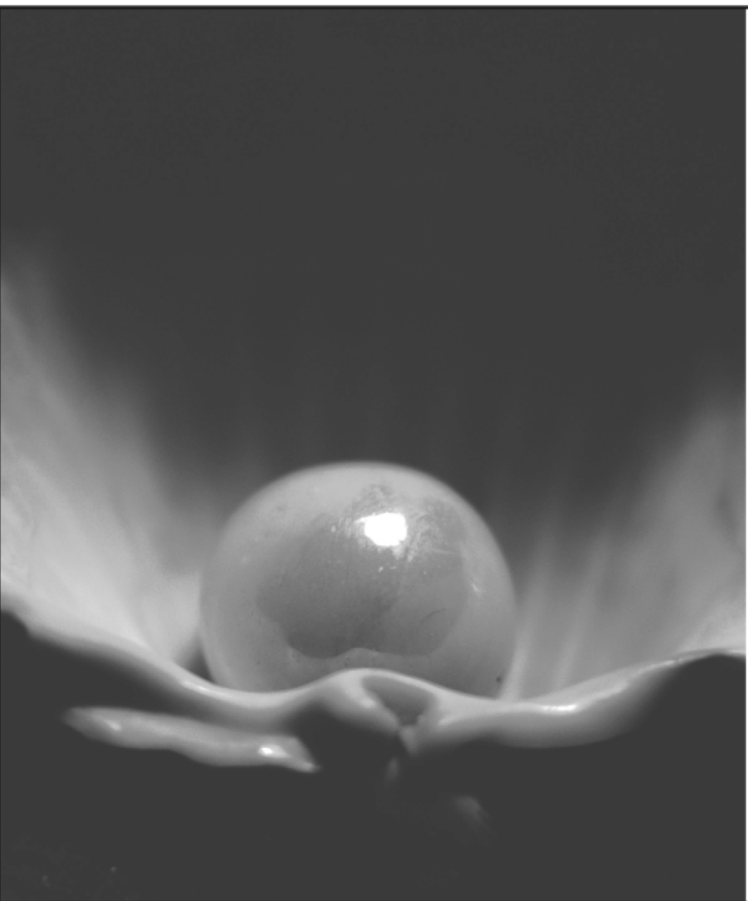

Looking for that SPeCial research paper from applied and technological aspects of the chemical sciences?

TRY this free news service:

\section{Chemical Technology}

- highlights of newsworthy and significant advances in chemical technology from across RSC journals

- free online access

- updated daily

- free access to the original research paper from every online article

- also available as a free print supplement in selected RSC journals.*

*A separately issued print subscription is also available.

Registered Charity Number: 207890 